JOURNAL DE PHYSIQUE

Colloque C6, supplément au $n^{\circ} 9$, Tome 46, septembre 1985

page $66-445$

\title{
HIGH FIELD MAGNETIZATION STUDY OF SODIUM-ZINC SPINEL FERRITES
}

X. Obradors, M. Pernet ${ }^{+}$, M. Vallet ${ }^{++}$, A. Isalgué, J. Rodriguez and

A. Labarta

Facultat de Física, Universitat de Barcelona, Diagonal 645, 08028 Barcelona, Spain

+Laboratoire de Cristallographie, C.N.R.S., associé à Z'U.S.M.G., 166 X, 38042 Grenoble Cedex, France

${ }^{++}$Departamento Química Inorgánica, Universidad Complutense de Madrid, Ciudad Universitaria, 28040 Madrid, Spain

Résumé - A partir des mesures d'aimantation et de diffraction des rayons $\mathrm{X}$ nous montrons que la structure magnétique des spinelles $\mathrm{Na}_{\mathrm{x}} \mathrm{Zn}_{1-2 \mathrm{x}} \mathrm{Fe}_{2+x^{\circ}}$

est non - collinéaire avec un angle moyen de canting supérieur à celui des spi nelles isomorphes $\mathrm{Li}$ - Zn. Les résultats experimentaux sont analysés dans le cadre d'un modèle modifié de spin canting. Le comportement de I'aimantation à saturation est bien reproduit avec ce modèle contrairement à la susceptibilité différentielle à fort champ. On en conclut que le modèle de spin canting est trop grossier pour expliquer certains resultats expérimentaux.

Abstract - From isothermal magnetization and $X$ - ray diffraction measurements it is shown that $\mathrm{Na} \mathrm{Zn}_{1-2 \mathrm{x}^{\mathrm{Fe}}} \mathrm{Z}_{2+\mathrm{x}} \mathrm{O}_{4}$ spinels own a non - collinear magnetic struc ture with a mean canting angle greater than the isomorphous Li - Zn spinels. The experimental results are analyzed in terms of a modified random spin canting model. The behaviour of saturation magnetization is well reproduced with this model but not that of the high field differential susceptibility. It is argued that the crudeness of the random spin canting model prevents a full explanation of the experimental results.

\section{I - INTRODUCTION}

Mixed spinel oxides are very interesting materials because the existence of competing antiferromagnetic interactions give rise to new magnetic phenomena such as spin glass behaviour /1/. For instance, from the early times of ferrimagnetism the existence of non collinear spin structure in disordered spinel ferrites was known and different theoretical models were proposed to account for it /2/. However, the magnetic behaviour of these compounds is complex and a correlation among experimental data arising from magnetization /2/, neutron diffraction /3/ and Mössbauer spectroscopy /4,5/ measurements is still lacking.

It was reported recently /6/ that new disordered spinels with composition $\mathrm{Na} \mathrm{Zn}_{1-2 \mathrm{x}} \mathrm{Fe}_{2+\mathrm{x}} \mathrm{O}_{4}$ can be prepared with the content $\mathrm{x}=0.25$. From a magnetic point of view these compounds could be considered equivalent to $\mathrm{Li}$ - $\mathrm{Zn}$ spinel ferrites, however, because of the greater size of $\mathrm{Na}$ ions the intrinsic magnetic properties may be strongly modified $/ 7 /$.

In this work we report a study of the low temperature saturation magnetization and differential susceptibility of $\mathrm{Na} \mathrm{Zn}_{2} \mathrm{Fe}_{2} \mathrm{O}_{4}$ spinels together with a $\mathrm{X}$ - ray diffraction investigation of cation distribution. Finally, a theoretical analysis of the experimental results is carried out in the scope of the spin canting model /2/.

\section{II - EXPERTMENTAL}

The synthesis procedure and elementary structural characterization of the Na - Zn spi nels were reported earlier /6/. Two series of compounds differing in their thermal treatments were prepared: i) A series with a slow cooling from $\mathrm{T}=1273 \mathrm{~K}$ at $\Delta \mathrm{T}=$ $50 \mathrm{~K} / \mathrm{h}$, ii) B series where the samples were quenched to liquid $\mathrm{N}_{2}$ from $\mathrm{T}=1273 \mathrm{~K}$. 
The isothermal magnetization curves of both series were measured at $T=4.2 \mathrm{~K}$ in magnetics fields up to $\mathrm{H}=150 \mathrm{KOe}$ by using the axial extraction technique in connection with a Bitter magnet of the Service National des Champs Intenses, Grenoble. The cation distribution of $\mathrm{A}-\mathrm{Na} 0.25^{\mathrm{Zn}} \mathrm{O} .5^{\mathrm{Fe}} 2.25_{4} \mathrm{O}_{4}$ compound was investigated from an X-ray diffraction pattern collected in an automatic Siemens D500 powder diffractometer using pyrolithic graphite monochromatised $\mathrm{CuK}_{\alpha}$ radiation. The explored angular range was $12^{\circ} \leqslant 2 \theta \leqslant 120^{\circ}$ and the angular step was $\Delta \theta=0.05^{\circ}$. The analysis of the diffraction pattern was carried out by the Rietveld method by using the DBW3.2 version of the Wiles and Young program $/ 8 /$. The crystal structure refinement was made with pseudo - Voigt profile for the diffraction"peaks and an overall isotropic temperature factor.

\section{III - RESULTS}

In Figure 1 the measured isothermal magnetization curves of A series compounds are shown. A similar set of measurements were carried out for the B series compounds. From these curves it is seen that magnetic saturation was reached, then in the high field region the magnetization curves may be represented by $M=M_{0}+X H$, where $M_{0}$ is the saturation magnetization and $\chi$ is the differential susceptibility.

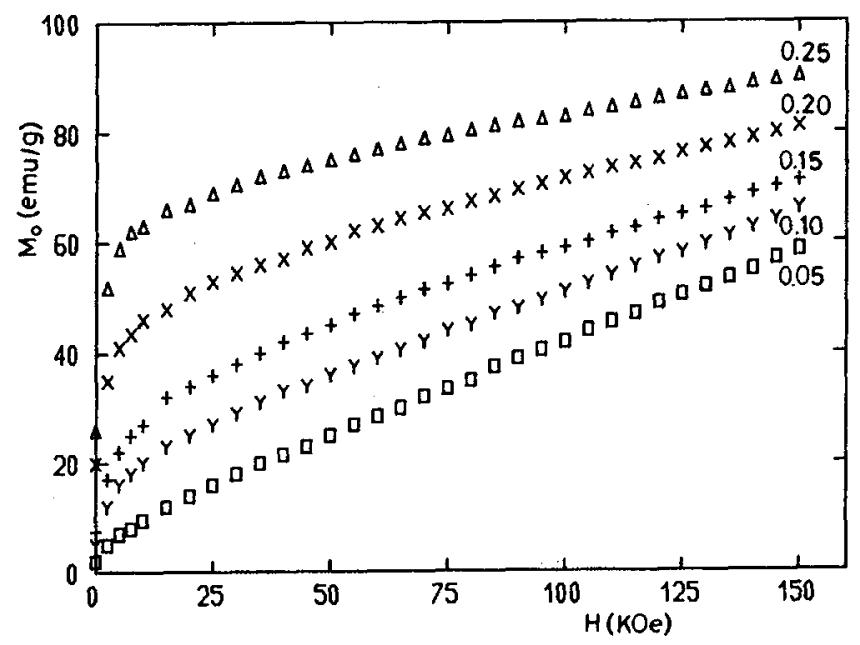

Fig. 1 - Isothermal magnetization curves of $\mathrm{A}-\mathrm{Na} \mathrm{Zn}_{1-2 \mathrm{x}} \mathrm{Fe}_{2+\mathrm{x}_{4}} \mathrm{O}_{4}$ spinels at $\mathrm{T}=4.2 \mathrm{~K}$.

In Figure 2 the composition dependence of $\mathrm{M}_{0}$ is indicated together with the values reported for $\mathrm{Li}$ - $\mathrm{Zn}$ spinel ferrites $/ 3 /$. The experimental values of $\chi$ are reported in Figure 3. The differences of $M_{0}$ and $\chi$ values among $A$ and $B$ series were lower than about $2 \%$. Then we may conclude that thermal treatment has a minor influence on the cation distribution and magnetic properties. In Table 1 we summarize the :e-

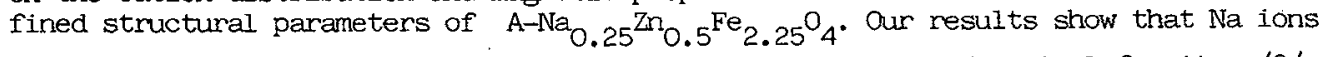
only occupy the octahedral B sites, similarly to Li in Li - Zn spinel ferrites /9/. The occupation of $\mathrm{Zn}(2+)$ ions, on the other hand, could not be conclusively stablished because of the small difference among $\mathrm{Fe}(3+)$ and $\mathrm{Zn}(2+)$ atomic form factors. If we assume that $\mathrm{Zn}$ ions only occupy the tetrahedral A sites, as in $\mathrm{Li}-\mathrm{Zn}$ spinel ferrites $/ 9 /$, the calculated saturation magnetization in the scope of a Néel type collinear spin structure is much higher than the experimental values. Hence, both the low values of saturation magnetization and the experimental high field differential susceptibility allow us to conclude that the spin structure of all the studied compounds is non collinear. 


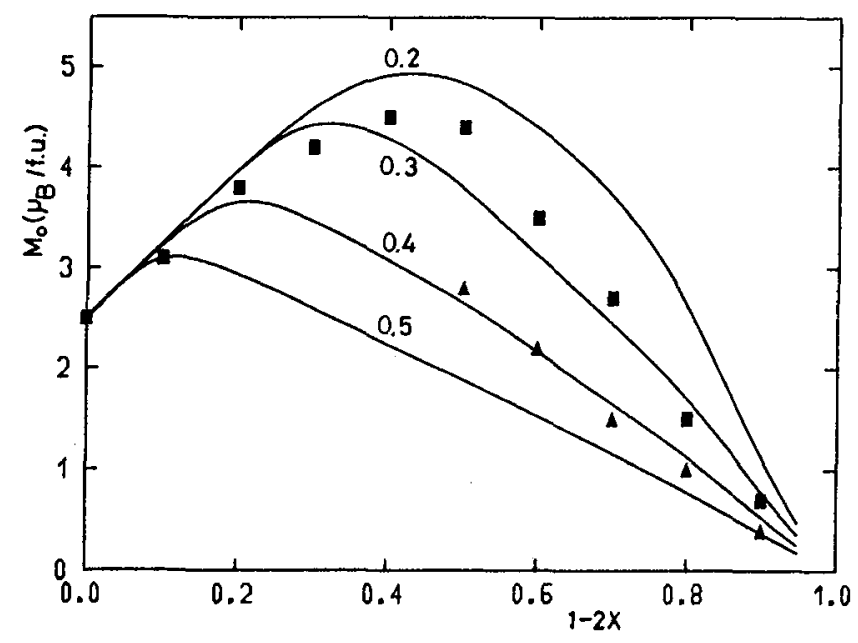

Fig. 2 - Saturation magnetization versus composition. $\triangle \mathrm{Na}$ - Zn ferrites, $\mathrm{Li}-\mathrm{Zn}$ ferrites. The lines are the results of the calculations with the indicated values of $\delta=J_{b b} / J_{a b}$, where $J_{b b}$ and $J_{a b}$ stand for octahedral-octahedral and tetrahedraloctahedral exchange interactions, respectively.

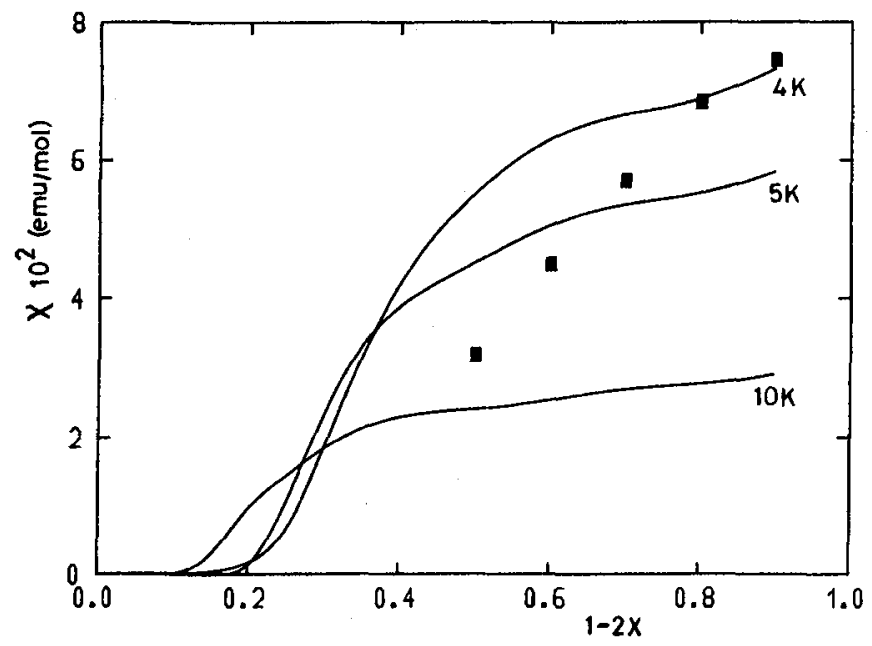

Fig. 3 - High field differential susceptibility as a function of the composition. The continous lines are the results of the calculations with $\delta=\mathrm{J}_{\mathrm{bb}} / \mathrm{J}_{\mathrm{ab}}=0.40$
and $\mathrm{J}_{\mathrm{ab}}$ values indicated.

\section{IV - RANDOM SPIN CANTING MODEL AND DISCUSSION}

In order to explain the non collinear magnetic structure of $\mathrm{Na}-\mathrm{Zn}$ spinels we have developped a theoretical analysis of the saturation magnetization and high field differential susceptibility in the scope of a modified random spin canting model. Our model assumes that the magnetic interactions may be represented with an isotropic Heisenberg Hamiltonian. In order to get self consistent local canting angles we have minimized : 
$F^{\prime}=F+\lambda\left(\cos \bar{\theta}-\sum_{i=0}^{6} p_{i} \cos \theta_{i}\right)$ where $\lambda$ is a Lagrangian multiplier which allows to maintain the self cosistency among $\theta_{i}$ and $\bar{\theta}$ values and $F$ is the free energy at $\mathrm{T}=\mathrm{O} \mathrm{K}$. We note that this formulation minimizes the total magnetic free energy and not the local magnetic energy. In Figure 2 the calculated $M$ values are shown for different $\delta=\mathrm{J}_{\mathrm{bb}} / \mathrm{J}_{\mathrm{ab}}$ exchange interactions ratios. It may be seen that an overall agreement among experimental and calculated values are got. We note, however, that the best $\delta$ values fitting the experimental data of $\mathrm{Na}-\mathrm{Zn}$ and Li - Sn spinels are quite different. Thus, it seems that the increase in the interatomic distances induced by $\mathrm{Na}$ ions lead to a modification of exchange integrals in such a way that an increase of the mean canting angle is produced. This is in agreement with the high sensibility of the non collinear ground states to small variations of exchange integrals $/ 7 /$.

Finally, we have calculated the composition dependence of the differential susceptibilities for different values of $J_{a b}$ (Figure 3 ). From the comparison of theoretical and experimental values it can be seen that even the qualitative behavioun is different. Thus, it appears that random spin canting models have a limited success in explaining the magnetic properties of the disordered spinel ferrites. Moreover, the spin glass behaviour previously reported $/ 10 /$, and which we have also observed in a set of experiments, now in progress, suggests that a deeper consideration of the exchange frustation effects must be done.

Table 1 - Cation distribution and crystallographic parameters of $\mathrm{A}-\mathrm{Na} 0.25^{\mathrm{Zn}} 0.5^{\mathrm{Fe}} 2.5_{4}^{\mathrm{O}}$

\begin{tabular}{lccccc}
\hline a $(\AA)$ & u & A site & B site & B $\left(\AA^{2}\right)$ \\
& & $0.5 \mathrm{Fn}$ & $0.25 \mathrm{Na}$ & \\
$8.4718(2)$ & $0.3883(3)$ & $0.5 \mathrm{Fe}$ & $1.75 \mathrm{Fe}$ & $0.33(4)$ \\
\hline
\end{tabular}

$R_{w p}=17.46 \% ; R_{E}=9.93 \% ; R_{B}=6.04 \%$

\section{REFERENCES}

/1/ Villain J., Z. Phys. B-Condensed Matter B33, 31 (1979).

/2/ Patton C.E., Liu Y., J.Phys. C-Solid State 16,5995 (1983).

/3/ Maltsev V.I., Vologin V.G., Phys.Stat.Sol (a) 85,529 (1984).

/4/ Dormann J.L., Rev.Phys. Appl. 15, 1113 (1980).

/5/ Barghava S.C., Zeman N. , Phys.Rev. B 21 , 1726 (1980)

/6/ Vallet M., Parras M., Obradors X., Pernet M. , Rodriguez J., Joubert J.C., I.E.E.E Trans. on Magn. MAG-2O, 1515 (1984).

$/ 7 /$ Globus A., Pascard H., Cagan V., J.Physique 38, C1-163 (1977).

/8/ Young R.A.,Wiles D.B., J.Appl.Cryst. 15, 430 (1982).

/9/ Nogues M., Dormann J.L., Perrin M., Simonet W., Gibort P., I.E.E.E. Trans. on Magn. MAG-15, 1729 (1979).

/10/ Patton C.E., Edmonson C.A., Liu Y.H., J.Appl.Phys. 53,2431 (1982). 